\title{
Desafios de adoção do livro didático de sociologia e formação continuada de professores
}

\section{Adoption challenges of the textbook of sociology and continuing education of teachers}

\author{
Thayene Gomes Cavalcante \\ Mestra em Ciências Sociais (FUNDAJ) \\ Professora de Sociologia (SSE/Paraíba) \\ thayene34@hotmail.com \\ Anicélia Ferreira da Silva \\ Mestra em Ciências Sociais (FUNDAJ) \\ Técnica em Assuntos Educacionais (IFP) \\ anicelia@pesqueira.ifpe.edu.br
}

\begin{abstract}
Resumo: Este artigo discute adoção do livro didático de sociologia e a política de formação continuada de professores em uma relação de reciprocidade. O livro didático de sociologia possui características e funções bastante instrutivas para o professor, especialmente no contexto de reintegração da Sociologia nos currículos do Ensino Médio. Pode mediar um discurso científico a um domínio cognitivo apropriado ao Ensino Médio, adquirir função de currículo, ou mesmo como formação ou informação de professores, entre outros atributos. No entanto, a adoção do livro didático pelos professores tem passado por alguns desafios, que envolvem, muitas vezes, questões formativas. Baseado em pesquisa realizada em João Pessoa-PB e Pesqueira-PE, com os professores de sociologia das referidas redes estaduais de ensino, durante o ano de 2015, a formação continuada de professores aparece como uma ferramenta política essencial para a adoção do livro didático de sociologia.
\end{abstract}

Palavras-chave: Livro Didático. Formação continuada. Professores. Ensino de Sociologia. Educação Básica.

\begin{abstract}
This paper discusses the adoption of textbooks of sociology and political continuing education teachers in a reciprocal relationship. The teaching of sociology book is instructive features and functions for the teacher, especially in the context of Sociology of reintegration in the curricula of high school. Can mediate a scientific discourse to a cognitive domain appropriate to high school, get resume function, or even as training or information for teachers, among other attributes. However, the adoption of textbooks by teachers has gone through some challenges, involving often training issues. Based on research conducted in João Pessoa-PB and Pesqueira-PE, with professors of sociology at state schools, during the year 2015, continuing education of teachers appears as an essential policy tool for the adoption of textbooks.
\end{abstract}

Keywords: Textbook. Continuing education. Teachers. Sociology of education. Basic education.

Originais recebidos em: 28/01/2016

Aceito para publicação em: 25/05/2016

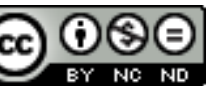

Este trabalho está licenciado sob uma Licença Creative Commons Atribuição-Uso NãoComercial-Vedada a criação de obras derivadas 3.0 Unported License. 


\section{Introdução}

Este artigo tem por objetivo discutir a relação entre a adoção do livro didático de sociologia e a formação continuada de professores. Foram realizadas duas pesquisas. Uma em João Pessoa - Paraíba, com professores da rede estadual sobre a adoção do livro didático de sociologia e, a outra, em Pesqueira - Pesqueira sobre os contextos e possibilidades de formação continuada para professores de sociologia. Ambas as pesquisas demonstraram a importância da política de formação continuada para o fortalecimento do ensino de sociologia na educação básica. E porque o livro didático está nessa discussão entre a formação e o ensino? Entende-se aqui que o livro didático tem funções e características muito importantes para a rotinização do pensamento sociológico (MEUCCI, 2007).

As supracitadas pesquisas realizadas durante os anos de 2014 e 2015 revelam muitas similaridades com relação aos problemas que envolvem a formação dos professores e o ensino de sociologia. Entrevistas e questionários foram realizadas com professores das respectivas redes estaduais de ensino, com a intenção de compreender os desafios que esta relação envolve. Em Pesqueira-PE os professores entrevistados foram os cursistas do Curso de aperfeiçoamento em Sociologia para o ensino médio, realizado pelo Instituto Federal de Pernambuco (IFPE) Campus Pesqueira e ofertado a professores da rede estadual nos municípios de Pesqueira e Garanhuns, de novembro de 2013 a maio de 2014. O curso contemplou professores de várias áreas de formação que atuam no ensino de Sociologia e mesmo os interessados que não atuam na disciplina. $\mathrm{O}$ requisito para participar do curso era que fossem professores da rede pública em regência de classe, mesmo que fosse contratado temporariamente. Na Paraíba, por sua vez, foram selecionados professores de acordo com modalidades diferenciadas de ensino ofertadas pela rede, com o intuito de perceber as variadas possibilidades de ensino da sociologia, de adoção do livro didático e as nuances entre essas modalidades.

Antes de expor os desafios encontrados na pesquisa - que envolvem a relação entre formação, ensino e livro didático - se faz necessário compreender quais são as funções do livro didático, a especificidade do ensino e do livro de sociologia, como se dá a adoção do livro do didático, as possibilidades de formação continuada e, por fím, o porquê dessa relação de reciprocidade entre as duas políticas públicas para o ensino de sociologia. 


\section{O livro didático e o ensino de Sociologia}

O livro didático tem significado importante para a difusão dos saberes das diversas áreas de conhecimento na escola. Ele possui características específicas e, com estas, funções igualmente vastas, especialmente no contexto de consolidação dos componentes curriculares da educação básica. Mesmo sendo destinado em primeira instância aos estudantes - com sua linguagem, seu caráter imagético, enredo e complexidade - o livro didático adquire fundamental importância também para os professores. Estes fazem a mediação entre a ferramenta didática e o aluno, esclarecendo os conteúdos, estimulando seu uso, leitura, pesquisa, acrescentando dados, explanando suas sugestões didáticas, entre outras formas de intervenção. Essa atuação é importante para o entendimento das políticas públicas educacionais e, nesse caso, das políticas públicas educacionais voltadas para o livro didático de Sociologia.

Assim como outros componentes curriculares do ensino médio, a Sociologia enfrenta vários problemas na educação básica pública. Porém, esta disciplina, ao lado da Filosofia, apresenta dificuldades peculiares devido a sua recente reinserção no currículo do ensino médio. Destacam-se como temas principais: problemas de metodologias na adaptação do conhecimento acadêmico para o didático, de carga horária baixa, de formação inicial e/ou continuada, de escolha e disponibilidade de materiais para aula, de definição de um currículo mínimo, de conhecimento e efetivação das orientações e parâmetros para a disciplina, etc, questão estas que parecem ser comuns à maioria das escolas brasileiras. Em certo aspecto, cada um desses problemas pode não ser necessariamente resolvido, mas minimizado por meio do livro didático que, gradativamente, tem sido objeto de pesquisas e de ações no Estado. Muitas vezes, o livro didático é utilizado como a bússola para os professores que não têm formação na área, ou mesmo para os que a têm, posto que, as questões supracitadas corroboram para que o ensino de Sociologia, no nível médio, seja executado de forma insólita, necessitando assim, de alguma orientação básica.

Essa orientação muitas vezes é obtida por meio do livro didático que, sendo o instrumento oficial - legitimado, palpável e do cotidiano para o ensino da disciplina ganha caráter formativo ou funciona como programa de curso. Isso ocorre porque há um grande debate sobre o que lecionar em Sociologia, quais conhecimentos são relevantes e quais os métodos mais pertinentes para a adequação das teorias científicas aos os estudantes da educação básica. 
O livro didático, aprovado pelo governo federal após criteriosa avaliação de especialistas da área - pelo Programa Nacional de Livros Didáticos (PNLD) -, parece esclarecer em muito esses dilemas e atender tais expectativas, dado que foi aprovado nos múltiplos pré-requisitos estabelecidos para sua admissão e distribuição por todo território nacional. O livro também pode adquirir função de currículo, norteando quais temas, conceitos, teorias (BRASIL, 2006) e possibilidades de abordagens, metodologias e recursos podem ser empregados nas aulas. Tem potencial para transpor um discurso científico a um domínio mais compreensível, adequado ao ensino médio, entre outros atributos que ampliam potencialidades para os professores. Além disso, é uma política pública de amplo alcance e de altos investimentos do Estado brasileiro no que tange à avaliação, compra e distribuição de exemplares às escolas públicas. Trata-se se de uma cifra de bilhões, onde o Estado brasileiro é responsável por metade desse faturamento (IPEA, 2007).

Agora imaginemos que após a formulação, avaliação e distribuição dos livros didáticos, com tamanho investimento financeiro e político e com todo esse potencial instrutivo supracitado, os livros não sejam adotados pelos professores nas aulas. Foi essa preocupação que motivou a presente reflexão.

\section{A adoção do livro didático}

A apresentação do Guia de Livros Didáticos do PNLD mostra vários sentidos que o verbo "adotar" abarca. Com base no dicionário Aurélio, explicita que adotar envolve: decidir-se por, escolher, preferir, seguir, abraçar, tomar, assumir, aceitar, acolher, pôr em prática, em uso, perfilhar, legitimar, passar a usar, aprovar, outorgar, admitir, aceitar, reconhecer, recorrer, valer-se (BRASIL, 2014a). Em conformidade com o guia, são esses sentidos que este artigo trata sobre a adoção do livro didático. Adoção envolve, portanto, desde o processo de escolha até a utilização em sala de aula, passando por leituras, estudos, planejamento, entre outros.

Iniciemos pelo processo de escolha. O Programa Nacional do Livro Didático 2015 estabeleceu critérios específicos para a seleção das obras de Sociologia, tendo em vista fortalecer princípios que vêm sendo almejados e, aos poucos, consolidados por meio da presença da Sociologia no ensino médio. São, em resumo, os seguintes: a interdisciplinaridade das ciências sociais, o rigor teórico e conceitual, a mediação 
didática, a apreensão do conhecimento sociológico pelo aluno e a autonomia do trabalho pedagógico pelo professor (BRASIL, 2014b).

Para alcançar estes princípios o Guia de Livros Didáticos de Sociologia do PNLD 2015 (2014a) estabeleceu os seguintes critérios para a aprovação das obras didáticas distribuídas nas escolas públicas:

1. Respeito à legislação vigente, como a LDB e as Diretrizes Curriculares para o Ensino Médio;

2. Qualidade das referências teórico-conceituais, ou seja, rigor na apresentação dos paradigmas e conceitos das ciências sociais (clássicos e contemporâneos);

3. Critérios didático-pedagógicos, que se subdividem em: conteúdos e exercícios. Com relação aos conteúdos se observa a linguagem, os argumentos e as estratégias de mediação didática. Com relação às atividades e exercícios se observa o potencial de despertar diferentes capacidades e a coerência com a abordagem;

4. A viabilidade das imagens (fotos, charges, ilustrações, gráficos, tabelas e mapas) no auxílio à aprendizagem. Observa-se a real potencialidade de reflexão que a imagem pode despertar naquele contexto, bem como se elas não reforçam estereótipos ou ideologias. Além disso, observam a qualidade da impressão da imagem e os devidos créditos ou fontes;

5. Cuidados com a ortografia, referências de fontes documentais, a coerência e o projeto gráfico que deve facilitar o manuseio do livro pelo estudante;

6. As orientações que o manual do professor oferece, bem como as possibilidades de uso e sugestões que este apresenta ao professor.

Importa-nos compreender de que maneira esses critérios são levados em consideração pelos professores ao escolher o livro que irão trabalhar nos três anos de vigência. O Guia do PNLD expõe estes critérios de avaliação justamente como pontos com o quais os professores deveriam observar em suas escolhas.

O manual do professor é outro elemento recomendado pelo PNLD para a escolha do livro didático. Ele tem a função de orientar a prática pedagógica, situá-lo na abordagem dos conteúdos, sugerir atividades e oferecer possibilidades de dinamização. Porém, na maior parte dos casos, ele não é lido, nem é bem visto pelos professores: "Sou criativa e tenho autonomia. O manual deixa a pessoa presa, fica mais produtivo o trabalho sem ele" (Professora de Sociologia em João Pessoa-PB, formação inicial em 
Geografia $^{1}$ ); "Não posso nem dizer que é bom ou que é ruim. Nunca li. Não sou dado a trabalhos com receitas" (Professor de Sociologia em João Pessoa-PB, formação inicial em filosofia).

Muitos relatos mostraram também que as escolhas das obras didáticas eram feitas de acordo com seus julgamentos e não baseadas na análise detalhada das obras: "Eu já sabia qual livro ia escolher, nem olhei os outros. Há anos sempre escolho os dessa editora" (Professora de Sociologia em João Pessoa-PB, formação inicial em Geografia).

Outras razões parecem nortear as escolhas dos professores. Uns parecem se interessar pelo imagético, como é o caso desta professora: “Observei a questão didática, as gravuras. Dou importância à imagem porque com ela dá pra dar uma aula e produzir um texto final, e isso enriquece a aula" (Professora de Sociologia em João Pessoa-PB, formação inicial em Ciências Sociais). Outra docente destaca que a preferência pela editora vem do fato dela ter uma linguagem menos técnica, com atividades que estimulam a participação do alunado (Professora de Sociologia em João Pessoa-PB, formação inicial em Geografia).

É no tempo ordinário da sala de aula que podemos perceber como se dá a utilização dos livros didáticos. Pensando de acordo com o Guia do PNLD, o bom uso do livro didático envolve a criatividade e o compromisso do professor, pois ele é o condutor, quem dá sentido à política pública educacional do livro didático. Para o Guia, o professor é central no trabalho de convencimento dos estudantes, posto que, é ele quem dá utilidade e pertinência ao livro didático (BRASIL, 2014b). Pois é justamente esse papel que ele desenvolve legitimamente, não com o mesmo raciocínio oficial, mas com uma lógica diferenciada. Vejamos alguns argumentos das falas de uma entrevistada, semelhante às de outras entrevistas, acerca da sua forma de adoção do livro didático: "O livro é para o aluno, não para os professores"; "Devemos exercitar a autonomia no ato de lecionar, e o livro didático engessa”; "O livro didático (sumário) é importante para registro de cadernetas"; "O livro didático não é tão atual como a internet" (Professora de Sociologia em João Pessoa-PB, formação inicial em Geografia).

\footnotetext{
${ }^{1}$ Na Paraíba, a Resolução No 101/2008 do Conselho Estadual de Educação habilita quais os profissionais podem lecionar as disciplinas na escola. No caso da Sociologia, os habilitados são os licenciados em Ciências Sociais ou em sociologia. Porém, na prática, a maioria dos profissionais não tem formação específica.
} 
Destacamos este último argumento. Os professores entrevistados costumam utilizar outros materiais didáticos e a internet é muito facilitadora disso. O argumento é que se pode encontrar temáticas que estão sendo discutidas na mídia e trabalhá-las nas aulas de sociologia, dado que é o ensino de sociologia na educação básica é o espaço de preparação para a cidadania. Fala-se também do teor resumido que a internet disponibiliza os conteúdos, "sem arrodeios" como alega uma entrevistada: "A internet condensa as informações e já deixa mastigadinho e no tempo limite para se trabalhar em uma aula semanal. Professor não pode perder tempo" (Professora de Sociologia em João Pessoa-PB, formação inicial em Geografia).

Os dois primeiros argumentos - que o livro didático é para o aluno e da autonomia do professor - demonstram o quanto o cotidiano da sala de aula escapa às pretensões das legislações. É comum, nos discursos, o professor utilizar a aula para que o aluno leia e resolva os exercícios sem necessariamente ter preparado aquela aula. Outra tática é pedir que os alunos leiam em voz alta os tópicos dos livros e falem o que entenderam. Estes dois métodos são defendidos pelo argumento de que a leitura do livro tem linguagem para os alunos, e que são estes que devem estudar o livro e não o professor. Com relação às sugestões didáticas, os professores tendem a rejeitá-las alegando a falta de tempo da aula, planejamento e estrutura da escola. Por isso "eu uso o livro como eu quero, e não como mandam" (Professora de Sociologia em João PessoaPB, formação inicial em Ciências Sociais).

O último argumento, talvez o mais inusitado, seja o do registro de aulas na caderneta através do sumário do livro. Essa tática é reveladora de como os livros têm sido utilizados em suas práticas cotidianas, muitas vezes foi colocado como dica: "Aí você pega o sumário, divide as unidades e registra as aulas. É uma mão na roda. Né isso que eles querem? E não é obrigado você trabalhar desse jeito na sua aula. Muitas vezes tenho que ficar 5 semanas com o mesmo tema, às vezes o bimestre. Por isso o livro ajuda muito, por que na verdade me colocaram aqui sem condições de lecionar a disciplina" (Professora de Sociologia em João Pessoa-PB, formação inicial em Geografia).

Nota-se, então, que as estratégias de usos do livro didático, pelos professores, são bem inusitadas e escapam às recomendações das prescrições oficiais. A inventividade e as engenhosidades ultrapassam as previsões e demonstram outra lógica norteadora: 


\begin{abstract}
A diretora chegou pra mim e falou: 'Eu pensei em você, inclusive não vou nem levar ofício dizendo que precisa de professor de Sociologia, que eu acho que se encaixa perfeitamente em você'. Aí foi muito que jogado assim. A primeira vez que fiquei com Sociologia ela disse: 'O livro de Sociologia é esse'. Eu disse: 'Vou fazer o que com isso?'. Era um laranjinha. Eu gosto demais dele. Nessa primeira fase ele ajudou demais porque me deu um norte. Depois que eu fui ficando mais familiarizada e passei a usar as coisas do dia a dia, as coisas mais práticas. Por exemplo com o tema bullying. Então assim eu terminei criando autonomia pra juntar com outras coisas, sair do livro de sociologia e trazer as questões de direito, por exemplo, e funcionou bem. Primeiro ano eu era cega. 'Meu Deus do céu como eu vou dar isso?' Completamente desorientada. Eu disse: 'Meu Deus esses meninos são minhas cobaias. O que é que eu vou ensinar pra esses meninos?'. Risos”. (Professora de Sociologia em João Pessoa-PB, formação inicial em História/Direito).
\end{abstract}

Para essa docente, o livro foi utilizado, de fato, como um guia num primeiro momento: (in)formando, apresentando sugestões didáticas, norteando sobre temas sociológicos, etc. No entanto, ao passo que se sentia mais íntima com a disciplina de Sociologia, ia desenvolvendo o que ela mesma chama de autonomia, que a distanciou, cada vez mais, do uso do livro didático em sala de aula:

Trago muito alguma coisa que eu acho interessante, tiro cópia em casa e
trago pra eles. Por que é uma dificuldade trabalhar com o livro. Além de eu
não gostar muito do livro, a questão dos meninos da noite, principalmente da
EJA, eles trabalham o dia todo e eles vêm direto pra escola. Então você exigir
'Amanhã todo mundo com o livro!', aí um traz e o outro não traz e diz
'Como é que eu vou passar o dia todinho trabalhando e voltar carregando um
livro?'. Então é uma dificuldade. Mas teve um tempo que eu disse 'Traga os
livros que eu fico com os livros de vocês na escola', porque fica melhor. Aí
fiquei com os livros presos na escola. Este ano ainda não fiz isso, mas é bem
provável que eu venha a fazer isso, por que é uma dificuldade pra esses
meninos trazerem os livros, Eu digo que eu não gosto muito, mas tem tema
que é interessante. Eu gostava mais do livro do ano passado. Mas não tem
como fugir do livro, ele é um guia, mesmo que você não goste muito".
(Professora de Sociologia em João Pessoa-PB, formação inicial em
História/Direito).

Embora reconheça que se sente mais à vontade em trabalhar conteúdos de seu domínio profissional, a docente admite a importância do livro didático para alguns momentos de sua prática, mesmo tendo diminuído seu uso. Porém, um ponto demonstra a distância entre a docente e o livro didático, quando ela relata que o livro utilizado anteriormente - "o laranjinha" (TOMAZI, 2010) - era utilizado por ela e ela gostava mais. Esse apreço pode estar atrelado ao fato de que ele teve um significado nesse processo de adaptação à nova realidade de lecionar a disciplina nova. Entretanto, ao dizer que não gosta do novo livro, passa despercebido que o livro adotado pela escola é o mesmo, em nova edição Sociologia para o Ensino Médio (TOMAZI, 2013), isso demonstra o quanto o livro é muitas vezes utilizado para suprir aulas não planejadas. Um dia, antes da entrevista, por exemplo, ao ter o primeiro contato com a professora, 
ela copiava no quadro trechos do livro de Sociologia, cuja referência ela não soube informar no dia seguinte durante a entrevista. Outro relato ilustra a mesma ideia:

Eu gosto de reunir em grupo e lemos uma parte do que traz o livro, depois elaboro questões sobre a leitura. Às vezes também pego o texto e faço uma aula expositiva lendo o assunto. Ler os tópicos é importante, porque ajuda o aluno a dar valor à leitura e o professor pode dar uma amarrada no assunto" (Professora, formação inicial em Ciências Sociais, modalidade de ensino Educação Profissional Integrada e Concomitante).

Ler trechos do livro ou copiá-los parece, então, uma tática muito utilizada para suprir a falta de planejamento. Vale destacar que existem diversas outras formas de adoção do livro didático relatadas nas entrevistas, que ilustram essa inventividade. Embora a criatividade e autonomia sejam destacadas pela política pública do PNLD, estas são surpreendentes e chegam a escapar às possibilidades previstas.

\section{A formação do professor nas aulas de Sociologia}

As práticas de adoção dos livros didáticos apresentam sutilezas nas abordagens dos professores. Vários fatores influenciam seus métodos e recursos didáticos no planejamento de aula. As abordagens variam de acordo com os valores, religiosidades, ou crenças e, muito fortemente de acordo com as formações acadêmicas dos professores.

A ênfase dos documentos oficiais é que conhecimentos da sociologia são importantes para a preparação para a cidadania (lei 9394/96, parecer CNE/CEB n ${ }^{\text {o }}$ 38/2006). A maioria dos professores entrevistados encara a sociologia de acordo com suas noções de cidadania, principalmente. No entanto, essa forma de perceber a disciplina pode gerar grandes confusões no tocante ao que pode ser considerado conhecimento sociológico que contribua para a cidadania dos jovens.

Santos (2002) percebeu em seu estudo que as concepções de cidadania variavam de acordo com as formações. O professor com formação em ciências sociais tende a enfatizar os conceitos e as teorias, já os de outras áreas do conhecimento destacavam a participação cidadã e a intervenção na realidade. E quando fala-se em formação para a cidadania, estão embutidas nos discursos ideias de um caráter instrutivo e ideológico da Sociologia na educação básica. Assim, as particularidades dos professores repercutem nas suas escolhas pedagógicas. Embora a defesa de uma preparação para a cidadania esteja presente, ela varia de acordo com suas ideologias. 
Uma professora entrevistada, cuja formação é na área ambiental, por exemplo, destaca o tema "meio ambiente" como principal a ser discutido pela sociologia. Já outra docente, que trabalhou anos no SENAI, no setor de recrutamento para o mercado de trabalho, e que atualmente leciona sociologia em uma escola profissionalizante, destaca a importância de preparação para o mercado de trabalho. Do mesmo modo, uma outra professora com formação na área de história e de direito, demonstra claramente que uma função importantíssima da sociologia é esclarecer questões referentes à justiça e direitos.

Eu não gosto muito do livro. Tem muitas coisas interessantes, mas eu prefiro trabalhar com coisa assim muito concreta, trabalhar com questão social mais próxima do aluno. Eu acho justamente por eu ter a formação em Direito também, trabalhar com a questão de direitos e deveres. Acontece alguma coisa e eu termino associando com a legislação em cima disso, trago isso pra sala. Mas eu trabalho muito com coisa extra. Eu sou professora de História e Sociologia, mas em algumas turmas a professora de História é outra e eu fiquei só com Sociologia. Aí eu levo pra andar, levo pra passear e ali eu termino discutindo as questões históricas e junto com as questões sociais. Faço muito um junto e misturado e tem dado certo, eles entram nesse mundo da discussão das questões sociais. Nos terceiros anos eu tô trabalhando Sociologia uma coisa que eu fugi completamente do livro o tema 'Formação e atribuições do Estado', o Estado de Direito, como é que está dividida a questão dos três poderes dentro do Estado, porque aí é interessante e eles terminam perguntando coisas do tipo 'Professores e como foi feito pra esses poderes contrabalancearem o outro?' ou 'Por que não tá funcionando na prática pra inibir a corrupção?'. Aí eu vou explicar porque um poder não está contrabalanceando o outro, onde está o poder judiciário que não está agindo pra frear as aberrações, o que está acontecendo dentro do poder executivo, dentro do poder legislativo e tem sido bem interessante. Então eu fujo do livro didático de Sociologia propriamente dito e trago coisas muito de fora para a sala. Já está planejado para as próximas aulas discutir a questão da menoridade penal, que é um projeto de lei que está no congresso nacional. E tem muita gente que acha que botar um jovem de 16 anos na cadeia vai resolver o problema da criminalidade. É uma ilusão muito grande. Então eu trabalho muito essas questões, acho que o curso de Direito me ajuda a trabalhar isso e isso torna interessantes, eles gostam, participam, fazem peças. Muitas vezes você ir só pro livro fica uma coisa muito pra lá e eu trago eles pra cá. À vezes eu me questiono 'Será que um professor com formação em Sociologia trabalharia exatamente desse jeito?’ Não sei. Talvez não. Talvez ele tivesse uma metodologia diferente, pelo fato de ter a formação acadêmica e eu não tenho a formação acadêmica em Sociologia. Mas tem dado certo. Eu tenho gostado, a direção tem gostado. E eles fazem peças teatrais, e fazem encenações com as questões sociais do dia a dia. É uma didática que pode não ser a definida por vocês que são sociólogos propriamente ditos, mas tá funcionando e eu acho que tá legal” (Professora de Sociologia em João Pessoa-PB, formação inicial História/Direito).

Nessa fala percebe-se - além da influência que a sua formação em história e em direito tem no planejamento de suas aulas - a falta de intimidade com os temas comuns da Sociologia no ensino médio, e com o próprio livro didático. A discussão proposta pela professora e, destacada como ausente no livro didático, é encontrada no livro 
didático adotado pela escola - Sociologia para o ensino médio (TOMAZI, 2013) - em quatro capítulos de uma unidade completa: o Estado Moderno; O poder e o Estado; Poder, Política e Estado no Brasil e A democracia no Brasil. Outro professor coloca a abordagem de sociologia na sala de aula como um trabalho de orientação e contribuição ao aluno em ser uma "pessoa melhor" (Professor de Sociologia em João Pessoa-PB, formação inicial em História). Este professor lecionara na educação prisional anteriormente e, deixa claro que, sua abordagem tentava auxiliar o sistema para que o indivíduo se reintegrasse e se adaptasse novamente à sociedade.

Compreendendo a Sociologia sob esta mesma linha de raciocínio, a professora que tem formação em Ciências Sociais, mas passou 29 anos lecionando geografia, coloca que o papel da escola é a formação cidadã. Para ela, um dos maiores problemas da escola é a falta de identidade jovem, pois o aluno não conhece seu papel social.

\begin{abstract}
A Sociologia não tem só o papel de contestar, deve se colocar nesse processo de formação cidadã e contribuir nele. A escola deve mudar não só com relação às tecnologias, mas tem responsabilidade social. A disciplina serve, então, pra ensinar a gente se relacionar, ouvir o outro. A Sociologia te questiona como ser humano. Não se deve esquecer essa questão: somos seres humanos e temos valores" (Professora de Sociologia em João Pessoa-PB, formação inicial em Ciências Sociais).
\end{abstract}

Para essa docente, o professor de Sociologia deve priorizar a formação dos valores, mais do que os conteúdos. Assim, o professor de Sociologia deveria priorizar a questão da cidadania, indagando inicialmente “Quem sou eu neste universo?”. Este deveria, inclusive, segundo a professora, ser tema do primeiro capítulo do livro didático.

Em João Pessoa-PB solicitamos que alguns docentes destacassem temas relevantes a serem abordados pelo livro de Sociologia no ensino médio, bem como nos seus planos de curso. Temas como "Educação para o Trânsito", "Sexologia/Sexualidade”, "Auto estima”, "Drogas", "Valor do corpo (gostar-se)", "Solidariedade", "Dignidade Humana", "Valores", "Cidadania para a vida" aparecem como temas e conteúdos que o livro didático de Sociologia deveria contemplar. Estes temas são destacados, pelos professores, como discussões importantes muito mais por seu caráter moral do que crítico. Outros temas e conteúdos, já presentes nos livros didáticos de Sociologia, são citados pelos professores como temas que o livro deveria abordar, demonstrando a falta de leitura e conhecimento mínimo do livro didático como instrumento de trabalho. São eles: "Conflitos sociais", "Ética", "Cidadania”, "Direitos e deveres", "Religião", "Educação”, "Direito”, "Criminalidade”, "Grupos sociais”, "Violência”, etc. 
A docente que tem formação em Ciências Sociais, ministra aula em uma escola profissionalizante e possui especialização em formação profissional, o que se adequa em muito à proposta da escola. Além disso, seu histórico com a disciplina de Sociologia foi sempre voltado à área de recursos humanos. Seu histórico no mercado de trabalho faz com que tenha a percepção de que a sociologia está atrelada à profissionalização e demonstra a relação sempre presente em sua vida entre a Sociologia e a profissionalização. Desse modo, ela destaca a importância de se discutir a questão do trabalho formal e informal, direitos trabalhistas, importância do mercado de trabalho e subemprego. No entanto, ela coloca esses temas como ausentes no livro didático, mesmo o tema estando destacadamente no capítulo 4 do livro adotado pela escola (ARAÚJO et al, 2013). Isso pode ser explicado pela falta de planejamento com base no livro didático, ou pelo anseio, demonstrado na entrevista, de que as abordagens do livro didático fossem mais instrutivas, que tivessem o caráter de formar o cidadão.

A docente com formação inicial em Geografia deixa bem claro sua religiosidade durante a entrevista. Tanto é que, o primeiro tema que ela destaca como importante é a Religião, mas não a reflexão ou a crítica sobre a religião, mas sim uma educação religiosa. Para ela, a Sociologia serve como educação para a vida, para a formação cidadã, posicionamento similar ao da docente com formação inicial em História/Direito e da docente com formação inicial em Ciências Sociais, que alegam estar numa "sociedade dos descartáveis", por isso seria importante utilizar a Sociologia para formar o jovem com base nos "bons valores". O docente com formação inicial em Direito/Psicologia/Teologia, por sua vez, destaca que os temas que são discutidos em suas aulas de sociologia "geralmente o livro didático traz, mas não como quero", demonstrando o quanto os interesses pessoais se sobrepõem aos do consenso curricular da disciplina no Brasil.

Na dissertação intitulada “A Sociologia no Ensino Médio e sua Articulação com as Concepções de Cidadania dos Professores”, Lima (2012) reflete, através de uma pesquisa com os professores que ministram aulas de sociologia no ensino médio de Recife-PE, que há duas categorias de entendimento dos professores acerca da importância da sociologia no ensino médio. Uma seria a sociologia contributiva para a "harmonia social", para o bom convívio entre as pessoas. Esta é a categoria das relações interpessoais. E outra categoria "coisas do mundo" em que a presença da sociologia nas séries do ensino médio ajudaria os estudantes no entendimento das estruturas sociais. Para a autora, na concepção sobre a importância da sociologia no ensino médio, 
enfatizada pelos professores entrevistados, a que mais ganha ênfase é a das relações interpessoais. A Sociologia compreendida por tais professores parece ser, desse modo, o lócus dos temas transversais. Embora pareça arbitrário, arrisco dizer que se anseia através da sociologia um caráter mais moral do que científico e, consequentemente, se espera que o livro didático de sociologia tenha um caráter mais instrutivo, com base em valores, do que reflexivo.

Em muitos momentos, o esforço dos professores em tentar demonstrar que utilizam outros recursos didáticos como elementos diferenciais para a sala de aula foi perceptível. No entanto, tais recursos foram colocados como os únicos possíveis dentro do pouco tempo disponível para preparação das aulas, já que são mais resumidos, menos profundos e trazem menos teorias, exigindo, assim, menor esforço do professor que não tem propriedade sobre essas teorias. São ainda, segundo as categorias analíticas de Certeau (1998), táticas cotidianas para driblar a falta de formação, planejamento, tempo, etc. Não questiono, com isso, a legitimidade dessas táticas, mas é importante reiterar que as políticas públicas devem ser pensadas em conjunto. Apenas a política do PNLD não resolve questões provocadas por um cotidiano intenso, múltiplo e imprevisível.

Uma docente, por exemplo, usa muito a internet para auxiliá-la. Segundo ela, a Sociologia é uma disciplina de atualidades e a internet é mais atualizada que o livro didático, geralmente discute temas que estão em pauta na mídia, tais como greves e movimentos sociais. Dessa forma/maneira, o uso do livro depende muito do propósito da aula. Quando a docente deseja que o aluno faça atividades, ou estude sem necessidade maior de sua orientação, usa o livro didático. Segundo ela, o livro tem uma linguagem voltada para o estudante e possui uma sequência de raciocínio que ele pode dar conta. Mas, em suas aulas expositivas, se fundamenta na internet e destaca que o livro é importante para o planejamento curricular e registro de aulas.

Ao falarmos sobre os conceitos, temas e teorias propostos pelas OCNEM (BRASIL, 2006) ela diz: “Os conceitos são bons pra serem utilizados nas aulas introdutórias, pois explicam o que é a Sociologia e para que serve, os temas devem ser tratados sempre os da atualidade e as teorias não cabem no ensino médio, devido a profundidade e complexidade" (Professora de Sociologia em João Pessoa-PB, formação inicial em Geografia).

Vemos nessa fala o quanto são importantes as políticas de formação para os professores que lecionam Sociologia. Sem as teorias sociológicas, qual o diferencial da Revista Em Debate (UFSC), Florianópolis, volume 13, p. 132-154, 2015. ISSNe 1980-3532 
disciplina no ensino médio? Será que ela não poderia ser substituída por qualquer outra? Caso esse modo de encarar a Sociologia se perpetue, os questionamentos acerca da pertinência dela tendem a aumentar. Desse modo, não basta que a disciplina seja lecionada nas escolas, ela precisa cumprir seus objetivos na educação básica. Mas será que esses objetivos estão claros até mesmo para os formuladores das políticas públicas educacionais? Parece-nos que não. E isso se reflete no dia a dia das salas de aula como esta. Da mesma forma, não basta uma política eficiente de distribuição dos livros didáticos, pois esta por si só não vai garantir o seu uso.

\section{Fortalecimento da Sociologia na Educação Básica com a Formação continuada}

No Brasil, existem diversos documentos que regulamentam as políticas de formação docente no âmbito dos sistemas públicos de ensino. Alguns deles tratam da formação continuada em nível nacional, estabelecendo diretrizes para a melhoria da educação. Dentre esses, é importante considerar o Decreto 6.755 de 29 de janeiro de 2009, o Plano Nacional de Pós-Graduação (PNPG) com vigência de 2011 a 2020 e, paralelamente, o Plano Nacional de Educação (PNE) de 2014, e a Resolução ${ }^{\circ} 2$, de $1^{\circ}$ de julho de 2015.

Este Decreto instituiu a partir de 2009 a Política Nacional de Formação de Profissionais do Magistério da Educação Básica, regulamentando a atuação da Coordenação de Aperfeiçoamento de Pessoal de Nível Superior (CAPES) no fomento a programas de formação inicial e continuada, e dá entre outras providências contidas nos incisos VIII, IX, X e XI de seu artigo $2^{\circ}$, os princípios da referida política de formação, no que se refere à formação continuada.

VIII - a importância do docente no processo educativo da escola e de sua valorização profissional, traduzida em políticas permanentes de estímulo à profissionalização, à jornada única, à progressão na carreira, à formação continuada, à dedicação exclusiva ao magistério, à melhoria das condições de remuneração e à garantia de condições dignas de trabalho;

IX - a equidade no acesso à formação inicial e continuada, buscando a redução das desigualdades sociais e regionais;

$\mathrm{X}$ - a articulação entre formação inicial e formação continuada, bem como entre os diferentes níveis e modalidades de ensino;

XI - a formação continuada entendida como componente essencial da profissionalização docente, devendo integrar-se ao cotidiano da escola e considerar os diferentes saberes e a experiência docente; 
O mesmo documento aponta os objetivos desta política no artigo $3^{\circ}$, cujos incisos II, III, IV, V e X se referem à formação continuada.

II - apoiar a oferta e a expansão de cursos de formação inicial e continuada a profissionais do magistério pelas instituições públicas de educação superior; III - promover a equalização nacional das oportunidades de formação inicial e continuada dos profissionais do magistério em instituições públicas de educação superior;

IV - identificar e suprir a necessidade das redes e sistemas públicos de ensino por formação inicial e continuada de profissionais do magistério;

$\mathrm{V}$ - promover a valorização do docente, mediante ações de formação inicial e continuada que estimulem o ingresso, a permanência e a progressão na carreira;

X - promover a integração da educação básica com a formação inicial docente, assim como reforçar a formação continuada como prática escolar regular que responda às características culturais e sociais regionais.

No artigo $8^{\circ}$, do parágrafo $1^{\circ}$ ao $6^{\circ}$ estão explícitas as formas de atendimento às necessidades de formação continuada.

\footnotetext{
Art. $80 \mathrm{O}$ atendimento às necessidades de formação continuada de profissionais do magistério dar-se-á pela indução da oferta de cursos e atividades formativas por instituições públicas de educação, cultura e pesquisa, em consonância com os projetos das unidades escolares e das redes e sistemas de ensino.

$\S 1^{\circ} \mathrm{A}$ formação continuada dos profissionais do magistério dar-se-á por meio de cursos presenciais ou cursos à distância.

$\S 2^{\circ}$ As necessidades de formação continuada de profissionais do magistério serão atendidas por atividades formativas e cursos de atualização, aperfeiçoamento, especialização, mestrado ou doutorado.

$\S 3^{\circ}$ Os cursos de atualização, aperfeiçoamento e especialização serão fomentados pela Coordenação de Aperfeiçoamento de Pessoal de Nível Superior - CAPES, deverão ser homologados por seu Conselho TécnicoCientífico da Educação Básica e serão ofertados por instituições públicas de educação superior, preferencialmente por aquelas envolvidas no plano estratégico de que tratam os arts. $4^{\circ}$ e $5^{\circ}$.

$\S 4^{\circ}$ Os cursos de formação continuada homologados pelo Conselho TécnicoCientífico da Educação Básica da CAPES integrarão o acervo de cursos e tecnologias educacionais do Ministério da Educação.

$\S 5^{\circ}$ Caso a necessidade por formação continuada não possa ser atendida por cursos já homologados na forma do $\S 4^{\circ}$, a CAPES deverá promover o desenvolvimento de projetos político-pedagógicos específicos, em articulação com as instituições públicas de educação superior.

$\S 6^{\circ}$ A CAPES disporá sobre requisitos, condições de participação e critérios de seleção de instituições e de projetos pedagógicos específicos a serem apoiados.
}

O PNPG é um documento que integra o PNE, abordando as questões relativas especificamente à pós-graduação e à pesquisa. Segundo os dados do Censo Escolar de 2013, apenas 30\% dos professores da Educação Básica têm pós-graduação. A formação continuada aparece como uma alternativa de suprir as lacunas da formação inicial, bem como oportunidade de desenvolvimento acadêmico e profissional do professor. Assim, 
o PNE estabelece que, até o final da vigência do plano, seja alcançada a meta de $50 \%$ dos professores com pós-graduação. A meta também estabelece a garantia da oferta de formação continuada na área de atuação dos professores, considerando as necessidades, demandas e contextualizações.

O PNE, aprovado pela Lei 13.005 de 25 de junho de 2014, tem vigência de 10 anos. A partir dele, os Estados, o Distrito Federal e os Municípios receberam as diretrizes que serviram para nortear a elaboração de seus próprios planos. As metas estabelecidas no documento são acompanhadas de estratégias e deverão ser cumpridas no período de vigência do plano, desde que não tenha sido estabelecido prazo inferior para seu cumprimento. Algumas instâncias estarão incumbidas do acompanhamento através de monitoramento contínuo e avaliações periódicas das ações. As metas 15, 16, 17 e 18 estão diretamente relacionadas aos profissionais da educação. A meta 15 aborda a elevação da escolaridade e a formação específica para atuar em determinada área, a meta 16 trata da formação continuada desses profissionais, a meta 17 ressalta a valorização profissional pela equiparação dos rendimentos e a meta 18 visa assegurar a existência dos planos de carreira. Sobre a formação continuada e pós-graduação de professores é estabelecido na meta 16 do PNE:

Meta 16: formar, em nível de pós-graduação, 50\% (cinquenta por cento) dos professores da educação básica, até o último ano de vigência deste PNE, e garantir a todos(as) os(as) profissionais da educação básica formação continuada em sua área de atuação, considerando as necessidades, demandas e contextualizações dos sistemas de ensino.

O termo formação continuada implica um aprimoramento constante e é necessário para obter-se êxito no exercício de qualquer profissão, devido ao crescimento e à velocidade com que os conhecimentos e informações se multiplicam atualmente. Os professores não estão fora desse contexto de exigências. Pelo contrário, sendo eles os profissionais do conhecimento, devem buscar cada vez mais o aprimoramento da formação profissional.

A meta $n^{\circ} 16$ do PNE privilegia a formação continuada em nível de pósgraduação, embora se entenda que são necessárias, diante do contexto da educação e dos fatores que atuam diretamente sobre os profissionais dessa área, outras formações de curta duração ofertadas, a fim de atender a situações de demandas emergenciais. Para alcançar esta meta foram propostas seis estratégias.

\section{ESTRATÉGIAS:}

Revista Em Debate (UFSC), Florianópolis, volume 13, p. 132-154, 2015. ISSNe 1980-3532 
16.1) realizar, em regime de colaboração, o planejamento estratégico para dimensionamento da demanda por formação continuada e fomentar a respectiva oferta por parte das instituições públicas de educação superior, de forma orgânica e articulada às políticas de formação dos Estados, do Distrito Federal e dos Municípios;

16.2) consolidar política nacional de formação de professores e professoras da educação básica, definindo diretrizes nacionais, áreas prioritárias, instituições formadoras e processos de certificação das atividades formativas; 16.3) expandir programa de composição de acervo de obras didáticas, paradidáticas e de literatura e de dicionários, e programa específico de acesso a bens culturais, incluindo obras e materiais produzidos em Libras e em Braille, sem prejuízo de outros, a serem disponibilizados para os professores e as professoras da rede pública de educação básica, favorecendo a construção do conhecimento e a valorização da cultura da investigação;

16.4) ampliar e consolidar portal eletrônico para subsidiar a atuação dos professores e das professoras da educação básica, disponibilizando gratuitamente materiais didáticos e pedagógicos suplementares, inclusive aqueles com formato acessível;

16.5) ampliar a oferta de bolsas de estudo para pós-graduação dos professores e das professoras e demais profissionais da educação básica;

16.6) fortalecer a formação dos professores e das professoras das escolas públicas de educação básica, por meio da implementação das ações do Plano Nacional do Livro e Leitura e da instituição de programa nacional de disponibilização de recursos para acesso a bens culturais pelo magistério público.

Fazendo uma comparação, grosso modo, a formação inicial pode ser entendida como uma introdução ou preparação para o exercício da profissão, enquanto que a formação continuada acontece cotidianamente, através de formações que promovam a qualificação dos profissionais, a melhoria da prática pedagógica, o domínio de métodos e conteúdos e o aperfeiçoamento da prática, na prática, a partir das próprias experiências e das experiências dos pares. Segundo Candau (1997, p.64):

\begin{abstract}
A formação continuada não pode ser concebida como um meio de acumulação (de cursos, palestras, seminários, etc., de conhecimentos e técnicas), mas sim através de um trabalho de reflexividade crítica sobre as práticas e de reconstrução permanente de uma identidade pessoal e profissional, em interação mútua. E é nessa perspectiva que a renovação da formação continuada vem procurando caminhos novos de desenvolvimento.
\end{abstract}

Nesse sentido, a Resolução $\mathrm{N}^{\mathrm{o}} 2$, de $1^{\mathrm{o}}$ de Julho de 2015, que institui as Diretrizes Curriculares Nacionais para a Formação Inicial e Continuada em Nível Superior de Profissionais do Magistério para a Educação Básica, é um documento de grande importância para a profissionalização dos professores no Brasil, uma vez que define diversos aspectos da formação, tanto inicial como continuada, conferindo aos profissionais do magistério um parâmetro único sobre o qual deverá ser construída a dinâmica de formação e de carreira. A definição das diretrizes, inclusive a avaliação e 
regulação das instituições que oferecem os cursos, garante maior qualidade na oferta, como também, evita que haja tantas discrepâncias entre um curso e outro.

Dentre as considerações que justificam a instituição dessas diretrizes, vale destacar algumas, cujo conteúdo valoriza tanto a formação inicial como a continuada, considerando que ambas são igualmente importantes.

CONSIDERANDO a necessidade de articular as Diretrizes Curriculares nacionais para Formação Inicial e Continuada, em Nível Superior, e as Diretrizes Curriculares Nacionais para a educação Básica;

CONSIDERANDO os princípios que norteiam a base comum nacional para a formação inicial e continuada, tais como: a) sólida formação teórica e interdisciplinar; b) unidade teórico-prática; c) trabalho coletivo e interdisciplinar; d) compromisso social e valorização do profissional da educação; e) gestão democrática; f) avaliação e regulação dos cursos de formação;

CONSIDERANDO A articulação entre graduação e pós-graduação e entre pesquisa e extensão como princípio pedagógico essencial ao exercício e aprimoramento do profissional do magistério e da prática educativa;

[...] CONSIDERANDO a importância do profissional do magistério e de sua valorização profissional, assegurada pela garantia de formação inicial e continuada, plano de carreira, salário e condições dignas de trabalho;

O Capítulo I Das Disposições Gerais, Artigo $1^{\circ}, \S 1^{\circ}$ enfatiza a necessidade de as instituições formadoras estarem em articulação com os sistemas de ensino em regime de colaboração, a fim de promover as formações de maneira que estas atendam às especificidades das diferentes etapas da educação básica.

É ressaltado no $\S 2^{\circ}$ e no $\S 3^{\circ}$ deste mesmo artigo que as instituições de ensino superior, bem como os centros de formação e as instituições educativas de educação básica que desenvolvem atividades de formação, devem conceber a formação inicial e continuada dos profissionais do magistério da educação básica articulada com as políticas e diretrizes da educação básica.

O Artigo $3^{\circ}$ destaca no $\S 3^{\circ}$ a formação docente como "um processo dinâmico e complexo, direcionado à melhoria permanente da qualidade social da educação e à valorização profissional". Sendo um processo dinâmico e permanente, fica ainda mais evidente a importância da formação continuada no desenvolvimento do professor enquanto profissional.

Os princípios da Formação dos Profissionais da Educação Básica são expostos no $\S 5^{\circ}$, incisos de I a XI do mesmo artigo, destacando o inciso X:

X - a compreensão da formação continuada como componente essencial da profissionalização, inspirado nos diferentes saberes e na experiência docente, 
integrando-a ao cotidiano da instituição educativa, bem como ao projeto pedagógico da instituição de educação básica.

O referido inciso aponta a formação continuada como essencial para a profissionalização docente, apontando a importância da integração na oferta desta formação. O capítulo II, no Artigo $5^{\circ}$ também faz a mesma observação, quando se refere a levar em conta a realidade dos ambientes das instituições educativas, buscando garantir o atendimento às especificidades de cada instituição. Além disso, ainda faz referência à articulação entre teoria e prática.

A condição do egresso dos cursos de formação é destacada no capítulo III, a partir do Artigo $7^{\circ}$ que elenca o que se espera como resultado, através da pluralidade de conhecimentos teóricos e práticos que serão consolidados no exercício da profissão.

Os capítulos IV e V enfatizam a constituição, a estrutura e o currículo dos cursos de formação inicial, visando garantir uma base comum nacional das orientações curriculares. No Artigo $16^{\circ}$ no capítulo VI a reflexão sobre a prática é considerada uma oportunidade de aperfeiçoamento técnico, pedagógico, ético e político do profissional docente. Nesse caso, vale salientar que a formação continuada, sendo uma atividade de professores em exercício, possibilita a reflexão "na e sobre" a prática.

A valorização dos profissionais do magistério é destacada no capítulo VII, Artigo $18^{\circ}$, que considera a formação como sendo um aspecto da valorização do magistério. O parágrafo $3^{\circ}$ parte da necessidade de garantir condições de trabalho de modo geral, com ênfase inclusive ao tempo destinado às atividades inerentes ao exercício do magistério e que muitas vezes consome muito mais tempo do profissional do que a aula propriamente dita.

No capítulo VIII, nas disposições transitórias, é determinado o prazo para adaptação dos cursos que estão em funcionamento a esta resolução, estabelecendo o prazo de dois anos a contar da data de sua publicação em julho de 2015. A organização dos cursos de formação inicial em áreas interdisciplinares será objeto de regulamentação suplementar, conforme preconiza o Artigo 24 deste capítulo.

A garantia de padrões mínimos para cursos tanto de formação inicial quanto continuada são explicitados em documentos como o Decreto 6.755, o PNE e a Resolução do CNE, visando garantir equidade de acesso e a qualidade nos cursos ofertados. 
Com base na pesquisa sobre Formação Continuada com professores de Pesqueira-PE, após um curso de aperfeiçoamento ofertado pelo IFPE campus Pesqueira, algumas percepções demonstram o quanto é desafiador, para a Sociologia na educação básica, superar os já citados dilemas que o ensino dessa disciplina enfrenta em particular.

Um desses problemas está na formação dos professores, dado que uma grande quantidade de professores de sociologia não tem formação na área, conforme exemplificam as próprias pesquisas presentes neste estudo. Como solucionar essa problemática que afeta a própria concepção do componente curricular? Acreditamos que a formação continuada tem condições de minimizar essa problemática de forma emergencial.

Os professores da pesquisa realizada em Pesqueira-PE afirmam a necessidade de complemento da formação continuada com ênfase nos conteúdos considerados mais complexos de se trabalhar em sala de aula, bem como se queixam, com frequência, da falta de tempo para socialização entre os pares.

Os professores, mesmo não concordando e, mesmo tendo frequentemente se deparado com formações pouco significativas para sua profissionalização, ainda buscam oportunidades de formação a fim de galgar mais degraus na escada do conhecimento. A busca pelo aprofundamento do conhecimento e pela melhoria da prática docente e consequentemente da melhoria do processo de ensino/ aprendizagem, ainda continua sendo um dos principais objetivos dos professores. $\mathrm{O}$ interesse em continuar um curso, ou mesmo em complementar uma formação antes iniciada pode ser interrompida pela descontinuidade do programa ou projeto, como muitas vezes ocorre.

Ambas as formas de formação, quer seja inicial ou continuada, são igualmente necessárias e importantes. Porém a discussão em torno da valorização da disciplina de Sociologia no âmbito das escolas por todos que a fazem, foi recorrente entre os pesquisados.

O grande desafio para os pesquisadores das Ciências Sociais/Sociologia é criar situações que promovam a discussão e as práticas formativas, que colaborem para o desenvolvimento das pesquisas nessa área e, ao mesmo tempo, elevem a qualidade do ensino. E, além disso, que por meio da formação dos professores, contribua para a permanência e consolidação da Sociologia como uma disciplina reconhecidamente privilegiada para oferecer o aporte teórico que venha a favorecer o desenvolvimento de saberes necessários à formação da consciência cidadã. 


\section{Considerações Finais}

Entendemos aqui que há uma relação necessária de reciprocidade entre a adoção do livro didático e a formação continuada dos professores, para a efetiva institucionalização do ensino de sociologia na educação básica.

A distribuição integral dos livros didáticos oferece elementos que possibilitam aos estudantes - dos mais variados espaços socioambientais, variadas classes sociais, diferentes culturas e hábitos de leitura - o acesso, de maneira igual, a uma forma legítima de difusão de um conhecimento, que é fruto de pesquisas e debates teóricos dos componentes curriculares. Ou seja, o conhecimento que é produzido nas universidades é traduzido e difundido - ou "rotinizado" como diz Meucci (2007) - para estudantes da educação básica de todo o Brasil. No entanto, se não for adotado pelos professores, a política para o livro didático estará sofrendo uma grande falha. Isso por que o livro didático funciona como forte instrumento minimizador das problemáticas particulares vividas pela Sociologia no ensino médio, mas não sendo adotado não estará contribuindo para a evolução desse quadro precário que a disciplina vem enfrentando.

A política de formação continuada aparece, então, como uma solução para que o professor adote o livro didático de sociologia, e este, por sua vez, assuma com propriedade sua função de mediador didático e de currículo. Por outro lado, a adoção do livro didático incentiva o professor a procurar melhores formas de se formar e lecionar.

Desse modo uma política para a adoção do livro didático aliada ao fortalecimento da formação continuada poderá contribuir para a consolidação da Sociologia no ensino médio e reversão desse contexto no qual a disciplina reforce sua credibilidade enquanto componente curricular de conteúdos, temas e teorias relevantes e essenciais para os jovens que estão no ensino médio. Caso permaneça sendo encarada apenas como uma disciplina complementar de carga horária, sem compreensão dos seus sentidos ideais, a sociologia não conseguirá atingir o patamar de aplicabilidade requerida para o ensino de sociologia na educação básica. Além disso é necessário que sejam pensadas políticas paralelas específicas de formação de professores, de didatização e de um currículo para a disciplina, sem que o livro didático seja sobrecarregado com a responsabilidade de encobrir lacunas de formação e capacitação. 


\section{Referências}

ARAÚJO, Silvia Maria [et al]. Sociologia. São Paulo: Editora Scipione, 2013.

BRASIL. Ministério da Educação. Secretaria de Educação Básica. Orientações curriculares para o ensino médio, na área de ciências humanas e suas tecnologias. Brasília, 2006.

BRASIL. Ministério da Educação (MEC). Módulo: Programas do Livro - PLi / Fundo Nacional de Desenvolvimento da Educação. Secretaria de Educação a Distância. 2.ed., atual. - Brasília: MEC, FNDE, SEED, 2008.

BRASIL. Planejando a Próxima Década: conhecendo as 20 metas do Plano Nacional da Educação, DF: Ministério da Educação, 2014.

BRASIL. RESOLUÇÃO $N^{o} 2$ de 01 de julho de 2015. Define as Diretrizes Curriculares Nacionais para a formação inicial em nível superior (cursos de licenciatura, cursos de formação pedagógica para graduados e cursos de segunda licenciatura) e para formação continuada.

BRASIL. Ministério da Educação. Secretaria de Educação Básica. Guia de livros didáticos. PNLD 2015: Apresentação: Ensino Médio. Brasília, 2014a.

BRASIL. Ministério da Educação. Secretaria de Educação Básica. Guia de livros didáticos. PNLD 2015: Sociologia: Ensino Médio. Brasília, 2014b.

CANDAU, V. M. F. Formação continuada de professores: tendências atuais. In:

CANDAU, V. M. (Org.). Magistério: construção cotidiana. Petrópolis: Vozes, 1997.

CERTEAU, Michel de. A invenção do cotidiano: artes de fazer. Petrópolis: Editora Vozes, 1998.

LIMA, Fabiana Conceição Ferreira de. A Sociologia no Ensino Médio e sua articulação com as concepções de cidadania dos professores. Dissertação de mestrado. UFPE: Recife, 2012.

IPEA. Compras governamentais para o Programa nacional do Livro Didático: uma discussão sobre a eficiência do governo. Texto 1307. Brasília, 2007. Disponível em: <http://www.ipea.gov.br/portal/images/stories/PDFs/TDs/td_1307.pdf>

MEUCCI, Simone. Sobre a rotinização da sociologia no Brasil: os primeiros manuais didáticos, seus autores, suas expectativas. Mediações, Londrina, v. 12, N. 1, p. 31-66, jan/jun 2007.

SANTOS, Mario Bispo dos. A sociologia no contexto das reformas do Ensino Médio. In: CARVALHO, Lejeune Mato Grosso de (org.). Sociologia e ensino em debate: experiências e discussão de sociologia no ensino médio. Ijuí: Unijuí, 2004. 
TOMAZI, Nelson Dácio. Sociologia para o ensino médio. 2 ed. São Paulo: Saraiva, 2010.

TOMAZI, Nelson Dácio. Sociologia para o ensino médio. 3 ed. São Paulo: Saraiva, 2013. 